\section{Capacitação profissional para o enfrentamento às violências sexuais contra crianças e adolescentes em Fortaleza, Ceará, Brasil}

\author{
Training health workers to deal with sexual abuse \\ of children and adolescents in Fortaleza, \\ Ceará State, Brazil
}

\author{
Formación profesional para la lucha contra la \\ violencia sexual en niños y adolescentes en \\ Fortaleza, Ceará, Brasil
}

\begin{abstract}
This study aimed to identify initiatives for training staff in the municipal healthcare system in Fortaleza, Ceará State, Brazil, to deal with cases of sexual abuse of children and adolescents. The reference for this exploratory study was the training program provided by the municipal government in 2010-2012 for administrators and health professionals in the public healthcare system in Fortaleza. At the time, the issue of sexual abuse was low in the system's training programs, despite recognition of its importance. Federal and State programs have provided input for such training programs in the various $\mathrm{mu}$ nicipal health departments. The main strategy was to invest in training for health workers in primary care. Social workers were found to have insufficient training, aggravated by temporary work contracts and high staff turnover. The study suggests the need for training to deal with violence, particularly sexual abuse.
\end{abstract}

Professional Training; Child Abuse; Sexual Violence
Suely Deslandes 1

Ludmila Fontenele Cavalcanti 2 Luiza Jane Eyre de Souza Vieira ${ }^{3}$ Raimunda Magalhães da Silva ${ }^{3}$

\section{Resumo}

Pretendeu-se identificar as iniciativas de capacitação aos profissionais da rede pública municipal de Fortaleza, Ceará, Brasil, para o enfrentamento de violências sexuais contra crianças e adolescentes. Esse estudo exploratório tomou como referência as capacitações ofertadas no biênio 2010-2012 pelo governo municipal para os gestores e profissionais que atuam na rede pública de Fortaleza. Constatou-se a baixa inserção da temática das violências sexuais nas capacitações ofertadas apesar do reconhecimento quanto à sua importância. Os programas federais e estaduais foram indutores das capacitações nas diferentes secretarias municipais. Considerouse estratégico o investimento do setor saúde na capacitação de profissionais da atenção básica. Em relação aos profissionais da assistência social, a insuficiência de capacitação é agravada pelas contratações temporárias e pela alta rotatividade. Sugere-se a construção de um plano de capacitação sobre violências e, em especial, sobre violência sexual.

Capacitação Profissional; Maus-Tratos Infantis; Violência Sexual 


\section{Introdução}

Estudos evidenciam que a violência sexual pode trazer danos à saúde física e mental de crianças e adolescentes 1. No Brasil, entre 2009 e 2013, foram registrados pelo setor saúde 62.390 casos de violência sexual contra crianças e adolescentes entre $<1$ ano a 19 anos (Departamento de Informática do SUS. Violência doméstica, sexual e/ou outras violências. htp://dtr2004.saude.gov.br/sinanweb/tabnet/ tabnet?sinannet/violencia/bases/violebrnet.def, acessado em 28/Out/2014).

A violência sexual é definida como todo ato ou jogo sexual envolvendo criança ou o adolescente e visando satisfação sexual de adultos ou pessoa em estágio de desenvolvimento psicossexual mais adiantado que a vítima. Apresenta-se sob múltiplas formas, das quais destacamos as mais conhecidas: exploração sexual, definida como a prática de obtenção de lucros ou benefícios na comercialização dos corpos de crianças e adolescentes para fins sexuais; abuso sexual, forma de violência sexual que geralmente circunscrevese ao universo de perpetradores que têm algum grau de responsabilidade sob os cuidados da criança. Outras designações de violência sexual contra o segmento infanto-juvenil são notadas: estupro, pedofilia e pornografia 2 .

O enfrentamento da violência sexual envolve esforços multidisciplinares, intersetoriais, interinstitucionais e multiprofissionais e a capacitação dos profissionais é reconhecida como ação estratégica 1 .

Apesar da busca por um modelo de formação de profissionais a partir de currículos comprometidos com a realidade, capaz de superar a visão disciplinar e responder à complexidade de fenômenos como a violência, a formação das diferentes profissões que atuam no campo das políticas públicas raramente inclui o tema da violência sexual 3 .

Diante das lacunas da formação na graduação, a educação permanente é uma necessidade, e, especialmente face às demandas que impactam o cotidiano de gestores e executores das políticas públicas de enfrentamento à violência sexual.

Nesse sentido, procurou-se identificar as iniciativas de capacitação ofertadas pelas secretarias da rede pública municipal de Fortaleza, Ceará, Brasil, aos seus profissionais para o enfrentamento de violências sexuais (sobretudo a exploração e o abuso sexual) contra crianças e adolescentes. Buscou-se inicialmente identificar as instituições que ofertaram as capacitações e as que não o fizeram, os temas abrangidos, a carga horária, público alvo atingido e as parcerias governamentais.

\section{Método}

Este estudo de caso de caráter exploratório faz parte do Projeto Multicêntrico Avaliação das Estratégias Governamentais Municipais no Enfrentamento da Exploração Sexual de Crianças e Adolescentes em Quatro Capitais das Macrorregiões Brasileiras.

O estudo de caso possibilita o aprofundamento exploratório, a compreensão do contexto tratado e a flexibilidade metodológica. Permite realizar descrições e aferir inferências sobre relações, fenômenos e práticas 4 .

Segundo informações do Disque Direitos Humanos - Disque 100, Fortaleza apresentou o maior índice de denúncias de exploração sexual (1.124), de 2003 a 2010, dentre as capitais do Nordeste.

A coleta de dados foi feita de julho a novembro de 2012 e tratou as capacitações ofertadas pelo governo municipal entre 2010-2012 para profissionais vinculados às secretarias de Saúde, Educação, Assistência Social, Direitos Humanos, Cultura, Esporte e Lazer e Guarda Municipal. Essas são apontadas pelas políticas públicas nacionais como responsáveis pelo enfrentamento da violência sexual contra crianças e adolescentes.

Realizaram-se entrevistas semiestruturadas com 22 gestores municipais dessas secretarias, foram transcritas e tomadas como fontes documentais orais. Os documentos escritos que caracterizassem as ações formativas mencionadas (relatórios de gestão) e as entrevistas foram categorizados segundo preceitos da análise temática 5 . As categorias temáticas foram: reconhecimento da relevância da capacitação; iniciativas relatadas e sua abrangência; conexões com esferas estaduais e federais de governo. $\mathrm{O}$ material empírico foi agrupado por setor e respectivas secretarias.

Essa pesquisa foi aprovada por Comitê de Ética e Pesquisa com parecer de no 6.354/2012.

\section{Resultados}

Participaram deste estudo 22 gestores com idade entre 25 e 55 anos, sendo 17 mulheres. Em relação à titulação, identificaram-se: mestres em saúde pública (quatro) e políticas públicas e planejamento (um); especialistas em consultoria organizacional (um); psicopedagogia (um); serviço social (um) e educação ambiental (um). A maioria apresentava média de quatro anos de exercício, evidenciando vinculação à gestão municipal reeleita para o período de 2009 a 2012.

Segundo a maioria dos gestores, as violências sexuais, especialmente a exploração sexual, não 
são abordadas nas capacitações, apesar do reconhecimento dessa necessidade.

Este entendimento é ratificado pelos gestores da Guarda Municipal e da Secretaria Municipal de Esporte e Lazer, que embora não tenham citado nenhuma iniciativa de capacitação, reconheceram a importância desta formação para os guardas e educadores físicos que atuam nos territórios com altos índices de violências.

A Secretaria de Direitos Humanos foi considerada pelos entrevistados como o principal gestor das capacitações ofertadas, seja pelo próprio município ou em parceria com as esferas federal e estadual.

Na educação, as iniciativas de capacitação sobre o tema vinculavam-se ao Programa Escola que Protege e ao Programa Educação para Combate à Exploração do Trabalho da Criança e do Adolescente (PETECA), respectivamente de esfera federal e estadual.

O Programa Escola que Protege, promovido pelo Ministério da Educação, foi iniciado em Fortaleza no ano de 2004 e interrompido em 2010. Entre 2008 e 2010, sob comando da Universidade Federal do Ceará, passou a incluir na oferta de formação outros profissionais da rede de educação, além dos professores e a carga horária passou a 120 horas.

O PETECA, implantado em 2009, abordava a exploração do trabalho infanto-juvenil, tratando apenas tangencialmente a questão da exploração sexual. Não estava disponível a informação quanto ao número de capacitados.

Gestor da Secretaria de Turismo mencionou a vinculação ao programa federal Turismo Sustentável e Infância como orientador do trabalho. Fortaleza foi piloto do Projeto Inclusão Social com Capacitação Profissional, que desde 2008 oferece cursos profissionalizantes para jovens em situação de vulnerabilidade social. O projeto promoveu a capacitação de 360 jovens de 16 a 26 anos. Todavia, não foram identificadas capacitações para os profissionais que atuam na cadeia de turismo.

Quanto à Secretaria Municipal de Saúde, desde 2007 têm sido ofertadas capacitações sobre a violência em geral e a sexual para os hospitais municipais, equipes de saúde da família (atingindo em 2010 77\% dos agentes comunitários de saúde) e Centro de Atenção Psicossocial. A parceria com o Ministério da Saúde, a partir do projeto Integrando as Redes de Apoio e Proteção à Criança e Adolescente, permitiu a capacitação de profissionais das redes de atenção, bem como os de outras secretarias.

Em 2012, foi realizado curso de 40 horas sobre violência sexual voltado aos profissionais do Hospital da Mulher (50 vagas). Foram abor- dadas as temáticas gênero e violência, violência sexual, abuso sexual infantil, rede de assistência, procedimentos de atendimento, aspectos legais, técnicos e éticos do abortamento e práticas em serviço.

Segundo representantes da Secretaria Municipal de Assistência Social, as equipes do Sistema Único de Assistência Social (SUAS) têm recebido capacitação sobre violência sexual de outras secretarias, especialmente da Secretaria de Direitos Humanos. A última capacitação foi oferecida em 2010, pelo Ministério Público. A rotatividade dos profissionais contratados (terceirizados) dos Centros de Referência de Assistência Social e Centros de Referência Especializado de Assistência Social, aliados à complexidade e imensa diversidade das demandas de atendimento, foram reconhecidos como desafios para a capacitação dos profissionais do SUAS.

\section{Discussão}

A necessidade de capacitação sobre violência sexual é reconhecida por gestores de todas as políticas públicas destinadas ao enfrentamento da violência contra crianças e adolescentes em Fortaleza. Todavia, o investimento nessas iniciativas é desigual entre as secretarias municipais e o registro precário. Observou-se como um limite desse estudo a insuficiência de informações institucionais que detalhem as capacitações, especialmente quanto ao número de profissionais atingidos e os conteúdos abrangidos. Poucas secretarias dispunham dessas informações elementares.

Segundo as principais políticas brasileiras de enfrentamento às violências sexuais, a capacitação contínua dos profissionais para a prevenção, identificação, notificação e atendimento é papel das secretarias e precisa ser tomada pelos programas de gestão municipal 6 .

O papel indutivo dos programas federais e estaduais, especialmente nos setores de turismo e educação foi marcante. Considerando-se a vocação turística da cidade, a capacitação dos operadores deste setor mostra-se necessária, especialmente no contexto de grandes eventos esportivos e culturais 7 .

O investimento da saúde na capacitação de profissionais da atenção básica é positivo e estratégico. Como aponta a literatura, os agentes de saúde e demais integrantes da Estratégia Saúde da Família têm importante papel para a prevenção e identificação precoce de situações de violência ${ }^{8}$. Todavia, se assinala a necessidade de igual investimento nos profissionais que atuam nos serviços hospitalares de referência. 
Os profissionais do SUAS, com missão definida de atendimento às situações de violência sexual ainda se mostram desguarnecidos de capacitação contínua e permanente em todo o país, o que se agrava com as contratações temporárias e rotatividade 9 .

Conclui-se que, apesar do reconhecimento formal das políticas quanto ao papel estratégico das capacitações de gestores e profissionais no enfrentamento das violências sexuais contra crianças e adolescentes, esse processo ainda é descontínuo, em alguns setores dependente dos investimentos estadual e federal e não envolve todas as secretarias municipais.

Sugere-se, por fim, a construção de um plano de capacitação sobre violências e, em especial, sobre violência sexual, tratando das formas de identificar e atuar nestas situações. Também é fundamental um investimento no registro institucional relacionado às ações de capacitação como ferramenta de gestão, permitindo o mapeamento dos conteúdos já abordados, as metodologias adotadas e a população abrangida.

\section{Resumen}

Se tenía la intención de identificar la oferta de capacitación a los profesionales del sistema público de Fortaleza, Ceará, Brasil, para luchar contra la violencia sexual en niños y adolescentes. El estudio exploratorio tomó como referencia las capacitaciones ofrecidas en el bienio 2010-2012 por el gobierno municipal a los directivos y profesionales que trabajan en el sector público de Fortaleza. Se halló una falta de inclusión del tema de la violencia sexual en las capacitaciones ofertadas, a pesar del reconocimiento de su importancia. Los programas federales y estatales fueron los responsables de la inclusión de dichas capacitaciones en los diferentes departamentos municipales. Se consideró también una inversión estratégica del sector de la salud en la capacitación de los profesionales de atención primaria. En relación con los profesionales de la atención social, la insuficiencia de capacitación es aún más grave, debido a las contrataciones temporales y la alta rotación. Se sugiere la creación de un plan de capacitación sobre la violencia y en particular sobre violencia sexual.

Capacitación Profesional; Maltrato a los Niños Violencia Sexual 


\section{Colaboradores}

S. Deslandes coordenou e elaborou o planejamento da pesquisa, coleta e análise dos dados bem como redigiu a comunicação breve. L. F. Cavalcanti, L. J. E. S. Vieira e R. M. Silva contribuíram para o planejamento da pesquisa, coleta e análise dos dados bem como da elaboração e revisão da comunicação breve.

\section{Agradecimentos}

Este trabalho foi financiado pelo CNPq e contou com a participação das pesquisadoras de campo Aline de Souza Pereira, Deborah Pedrosa Moreira, Kerma Márcia Freitas e Samira Valentim Gama Lira do Programa de Saúde Coletiva da Universidade de Fortaleza (UNIFOR).

\section{Referências}

1. Nogueira Neto W. Sexualidade infanto-adolescente e seu reconhecimento como direitos humanos: a necessidade de mais reflexão e teorizações. Psicol Clín 2012; 24:15-32.

2. Lowenkron L. Abuso sexual infantil, exploração sexual de crianças, pedofilia: diferentes nomes, diferentes problemas? Sexualidad, salud y sociedade. Sexualidad, Salud y Sociedad - Revista Latinoamericana 2010; 5:9-29.

3. Souza CM, Adesse L. Violência sexual no Brasil: perspectivas e desafios. Brasília: Secretaria Especial de Políticas para as Mulheres; 2005.

4. Yin RK. Estudo de caso: planejamento e métodos. 2a Ed. Porto Alegre: Editora Bookmam; 2001.

5. Gribs G. Análise de dados qualitativos. Porto Alegre: Editora Artmed; 2009.

6. Ministério da Saúde. Linha de cuidado para a atenção integral à saúde de crianças, adolescentes e suas famílias em situação de violências: orientação para gestores e profissionais de saúde. Brasília: Ministério da Saúde; 2010.
7. Childhood Brasil. Projeto Copa do Mundo de 2014: prevenção e enfrentamento à exploração sexual de crianças e adolescentes no contexto do mundial. São Paulo: Childhood Brasil; 2012.

8. Conselho Nacional de Secretarias da Saúde, Ministério da Saúde. O desafio do enfrentamento da violência: situação atual, estratégias de propostas. Brasília: Conselho Nacional de Secretarias da Saúde, Ministério da Saúde; 2008.

9. Conselhos Regionais de Serviço Social, Conselho Federal de Serviço Social. Trabalhar na assistência social em defesa dos direitos da seguridade social. Contribuições do conjunto CFESS-CRESS ao debate sobre definição de trabalhadores da assistência social. Brasília: Conselhos Regionais de Serviço Social, Conselho Federal de Serviço Social; 2011.

Recebido em 20/Mai/2014

Versão final reapresentada em 31/Out/2014

Aprovado em 01/Dez/2014 